\title{
Formation and Characterization of Carbon and Nickel Oxide/Carbon Composites for Supercapacitors
}

\author{
Z. Kavaliauskas ${ }^{a, b, *}$, L. MarcinaUskas ${ }^{a, c}$ And P. VAlatkevicius ${ }^{a}$ \\ ${ }^{a}$ Lithuanian Energy Institute, Breslaujos 3, LT-4440, Kaunas, Lithuania \\ ${ }^{b}$ Kaunas University of Applied Sciences, Pramonès 20, LT-50468, Kaunas, Lithuania \\ ${ }^{c}$ Kaunas University of Technology, Studentu 50, LT-51368, Kaunas, Lithuania
}

\begin{abstract}
In this study a carbon and $\mathrm{NiO} /$ carbon electrodes were prepared and investigated. The surface roughness increases with the increase of the torch power. The addition of the $\mathrm{NiO}$ changes the surface structure from a snowflake-like to a mesh-like. It was demonstrated that the addition of the nickel oxide to amorphous carbon increases the specific capacitance of composite electrode. However, the $\mathrm{NiO} /$ carbon electrodes have a lower breakdown voltage values and longer charge-discharge cycles.
\end{abstract}

PACS: 81.15.-z, 81.05.U-, 68.55.J-

\section{Introduction}

Supercapacitors have been extensively studied in recent years due to their high power density, long cycle life, and short charge time [1,2]. The transition metal oxides ( $\left.\mathrm{NiO}, \mathrm{RuO}_{2}, \mathrm{MnO}_{2}, \mathrm{IrO}_{2}\right)$, conducting polymers, and carbon based materials (carbon black, carbon nanotubes, glassy carbon, activate carbon) are widely used as the electrode materials of supercapacitors [1-5]. The application of carbon materials is very attracting due to high surface porosity leading to high surface area. The other advantages are: high temperature stability, conductivity, and chemical resistance $[1,3]$. Recently much attention is focused on the investigation of supercapacitors where electrode material combines the metal oxides $\left(\mathrm{RuO}_{2}, \mathrm{IrO}_{2}, \mathrm{NiO}, \mathrm{MnO}_{2}\right.$ and etc. $)$ and carbon based materials $[2,4,5]$. The addition of metal oxide on the carbon surface improves the capacitance values and increases the energy density. The nickel oxide due to its inexpensive price and pseudo capacitance behavior similar to $\mathrm{RuO}_{2}$ can be successfully used to improve the capacitance value of the carbon electrodes [4-6].

In this paper an experimental work was done to investigate the effects of torch power and $\mathrm{NiO}$ layer on the surface morphology and electrical parameters (capacity, breakdown voltage, and charge-discharge time) of carbon and $\mathrm{NiO} /$ carbon electrodes.

\section{Experimental setup}

The carbon was deposited on the stainless steel 1X18H9T substrates at the atmospheric pressure using a direct current plasma torch. More details about the

\footnotetext{
* corresponding author; e-mail: zydrunas@mail.lei.lt
}

plasma torch and deposition process can be found elsewhere [7]. Argon (Ar) was used as the plasma working gas with a flow rate of $6.6 \mathrm{l} / \mathrm{min}$. An acetylene $\left(\mathrm{C}_{2} \mathrm{H}_{2}\right)$ was used as precursor with a flow rate of $0.165 \mathrm{l} / \mathrm{min}$. The distance between the plasma torch and substrate was $0.005 \mathrm{~m}$, the coatings deposition time $-300 \mathrm{~s}$, and torch powers were $750 \mathrm{~W}$ and $870 \mathrm{~W}$. The $\mathrm{NiO}$ layer was deposited by the magnetron sputtering. The magnetron voltage was $280 \mathrm{~V}$, current $-1 \mathrm{~A}$, pressure of the oxygen gas $1.36 \div 1.85 \mathrm{~Pa}$. The deposition time was $60 \mathrm{~s}$, and it led to the growth of nickel oxide film with thickness of $72 \mathrm{~nm}$, or $\approx 300 \mu \mathrm{g}$.

The surface morphology was analysed by scanning electron microscopy (SEM) model JEOL JSM-5600. The structure was characterized by the Raman scattering spectroscopy (Ivon Jobin spectrometer using Spectra-Physics Nd:YAG laser $(532.3 \mathrm{~nm}, 50 \mathrm{~mW}$, spot size $0.32 \mathrm{~mm}$ )) and X-ray diffraction (XRD) (DRON-UM1, BRUKER D8Advance). Concentrated potassium alkali $10 \mathrm{M} \mathrm{KOH}$ was used as electrolyte. The charge-discharge curve measurements at a constant current $(150 \mathrm{~mA})$ were carried out on unit cell capacitor.

\section{Results and discussion}

The surface morphology of the carbon structure consists of $\approx 30 \mu \mathrm{m}$ diameter columns. Each column is composed of the fuzzy and snowflake-like structure. The column diameters become large (up to $50 \mu \mathrm{m}$ ), however the surface structure remains unchanged when the torch power increases. The deposited carbon structure contains deep holes between the individual columns (Fig. 1a). It was observed that the increase of torch power increases the surface roughness. The surface consists of a mesh-like structure after the deposition of $\mathrm{NiO}$ layer (Fig. 1b). 

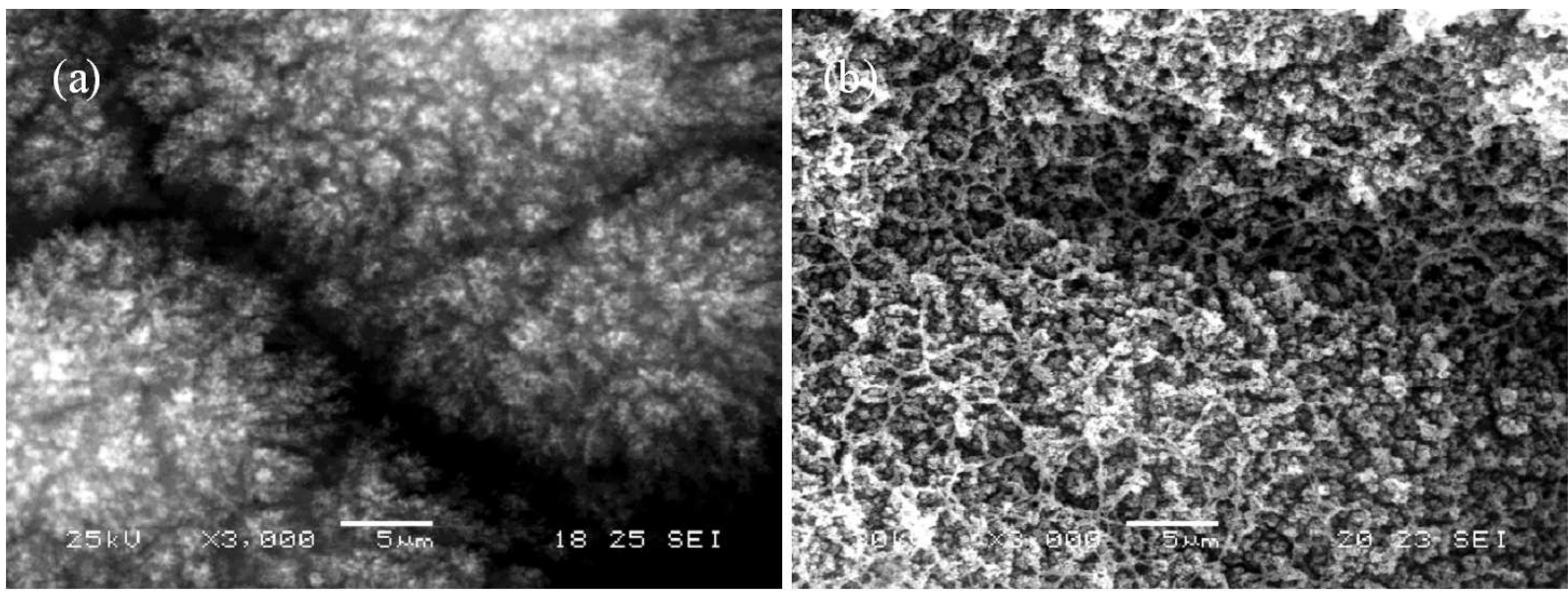

Fig. 1. The surface morphology of carbon coatings deposited at $870 \mathrm{~W}$ torch power (a) without $\mathrm{NiO}$, (b) with $\mathrm{NiO}$.

The XRD patterns of carbon electrodes show only a very broad peak indicating the amorphous carbon phase. The XRD analysis indicated a low intensity peak at $2 \theta \approx 43.2^{\circ}$, corresponding to $(200)$ diffraction plane of cubic structure of nickel oxide after loading the $\mathrm{NiO}$ on the carbon. The Raman spectra of carbon coatings are presented in Fig. 2. The coating prepared at $750 \mathrm{~W}$ power consists of the two separated peaks; $D$ centred at $1336 \mathrm{~cm}^{-1}$ and $G$ at $1581 \mathrm{~cm}^{-1}$ (Fig. 2). The full width at half-maxima (FWHM) of the $D$ is around $\approx 301 \mathrm{~cm}^{-1}$ and $G$ is $\approx 122 \mathrm{~cm}^{-1}$. The ratio of $I_{\mathrm{D}} / I_{\mathrm{G}}$ intensities is approximately 1.32. The carbon layer deposited at $870 \mathrm{~W}$ shows the D peak situated at $1370 \mathrm{~cm}^{-1}$ and $G$ at $1596 \mathrm{~cm}^{-1}$. The increase of the torch power influences the narrowing of the FWHM for $D\left(274 \mathrm{~cm}^{-1}\right)$ and $G\left(86 \mathrm{~cm}^{-1}\right)$ peaks. As a result the $I_{\mathrm{D}} / I_{\mathrm{G}}$ ratio increases up to 2.51 . The higher $I_{\mathrm{D}} / I_{\mathrm{G}}$ ratio demonstrates the increase of the graphite-like component in the amorphous carbon coatings and the $s p^{2}$-bonded carbon clusters size [8]. It may be noted that both deposited carbon coatings are amorphous and consist of the $s p, s p^{2}$, and $s p^{3}$ carbon site mixtures.

The specific capacitances of the carbon layers were equal to $1.82 \mathrm{~F} / \mathrm{g}$ at $750 \mathrm{~W}$ and $1.80 \mathrm{~F} / \mathrm{g}$ at $870 \mathrm{~W}$. It may be noted that the specific capacitance increases more than sixth times (up to $11.8 \mathrm{~F} / \mathrm{g}$ ) when the nickel oxide was deposited on the carbon electrode prepared at $750 \mathrm{~W}$. Meanwhile, the specific capacitance of the $\mathrm{NiO} /$ carbon composite, when the carbon coating was prepared at $870 \mathrm{~W}$ reached even $53.6 \mathrm{~F} / \mathrm{g}$ value. Tai and Teng [4] and Ito et al. [6] also demonstrated that the specific capacitance of the carbon based materials increases with the addition of the $\mathrm{NiO}$. The increase of the specific capacitance for the $\mathrm{NiO}$ /carbon electrodes is explained in such way. The impregnation of the carbon by the $\mathrm{NiO}$ produces the Faradaic pseudo-capacitance. At the same time the carbon structure due to a high specific area can provide a large double-layer capacitance. Thus, the spe-

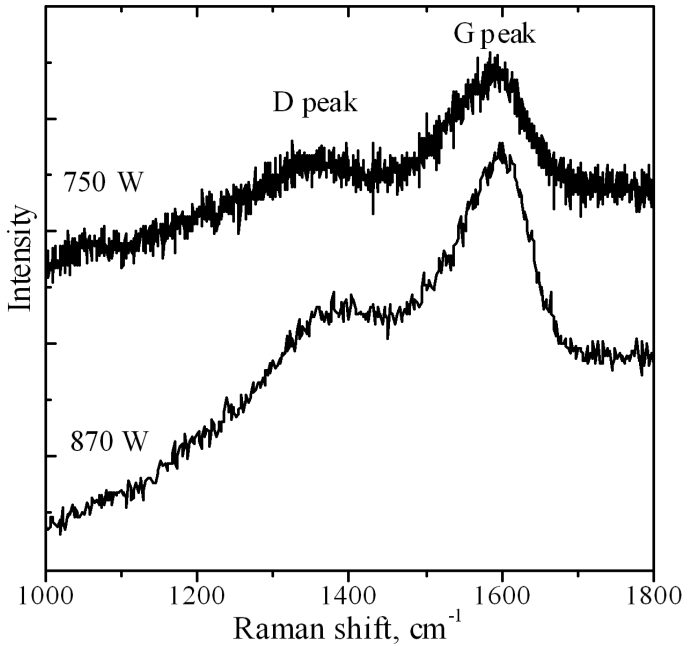

Fig. 2. The Raman spectra of carbon coatings.

cific capacitance of nickel oxide/carbon composite electrode increases [1].

The measurements indicated that the breakdown voltages of the carbon coatings deposited at $750 \mathrm{~W}$ and $870 \mathrm{~W}$ are $0.54 \mathrm{~V}$ and $0.52 \mathrm{~V}$, respectively. Meanwhile, when the $\mathrm{NiO}$ was deposited, the breakdown voltage decreases up to $0.36 \mathrm{~V}$ and $0.40 \mathrm{~V}$ for the carbon coatings prepared at $750 \mathrm{~W}$ and $870 \mathrm{~W}$, respectively. So, the charge-discharge behaviour of the carbon electrodes in the potential range between $0 \mathrm{~V}$ and $0.5 \mathrm{~V}$ at $150 \mathrm{~mA}$ was measured considering the breakdown voltage results. The charge-discharge times of the carbon electrodes are very similar due to almost the same capacity values (Fig. 3). It may be noted that the curves vary nearly linearly with the time demonstrating a good capacitive behaviour [9]. The charge-discharge curves of the $\mathrm{NiO}$ /carbon electrodes were measured in the poten- 
tial range between $0 \mathrm{~V}$ and $0.35 \mathrm{~V}$ at $150 \mathrm{~mA}$ current. It was found that the charge-discharge cycle of the $\mathrm{NiO} /$ carbon electrodes prepared at $750 \mathrm{~W}$ and $870 \mathrm{~W}$ lasts $70 \mathrm{~s}$ and $320 \mathrm{~s}$, respectively. Also the $\mathrm{NiO} /$ carbon curve was not as well-shaped triangle. This happens when the redox pseudo-capacitance arises and due to the existence of ohmic resistance of the cell [1].

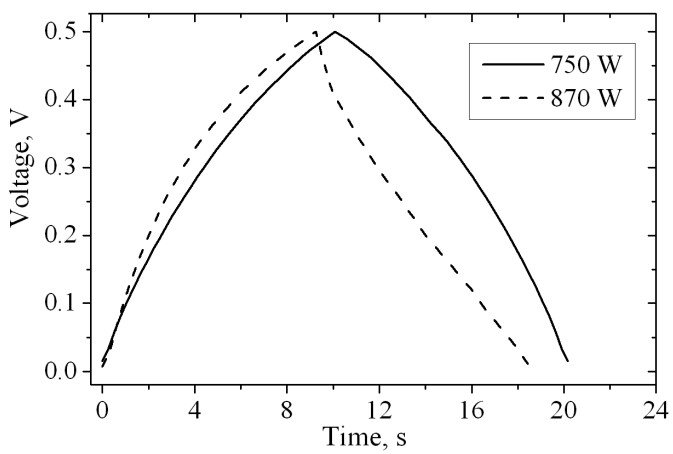

Fig. 3. The charge--discharge curves of carbon capacitors.

\section{Conclusions}

The carbon and nickel oxide/carbon composite electrodes were obtained and investigated. It was demonstrated that the increase of the torch power increases the surface roughness and the $s p^{2}$ carbon sites fraction in the carbon electrodes. However, it has no effect on the specific capacitance values. The impregnation of the nickel oxide changes the surface morphology from the snowflake-like to the web-like. The highest specific capacitance (up to $53.6 \mathrm{~F} / \mathrm{g}$ ) was obtained for the $\mathrm{NiO} /$ carbon composite, when the carbon was deposited at $870 \mathrm{~W}$. The breakdown voltages of the carbon electrodes are higher than the $\mathrm{NiO} /$ carbon composites. The charge-discharge cycle of the $\mathrm{NiO} /$ carbon composite electrodes lasts longer compared to the carbon electrodes.

\section{Acknowledgments}

The research was partly supported by the European Union (European Regional Development Fund).

\section{References}

[1] A. Pandolfo, A. Hollenkamp, J. Power Sources 38, 11 (2006).

[2] R. Kotz, M. Carlen, Electrochim. Acta 45, 2483 (2000).

[3] V.V.N. Obreja, Physica E 40, 2596 (2008).

[4] Y.L. Tai, H. Teng, Carbon 42, 2329 (2004).

[5] H. Li, Y. Li, R. Wang, R. Cao, J. Alloys Comp. 481, 100 (2009).

[6] E. Ito, S. Mozia, M. Okuda, T. Nakano, M. Toyoda, M. Inagaki, New Carbon Mater. 22, 321 (2007).

[7] L. Marcinauskas, A. Grigonis, V. Valincius, P. Valatkevičius, Mater. Sci. 13, 269 (2007).

[8] J. Robertson, Mater. Sci. Eng. B 37, 129 (2002).

[9] Y.F. Su, Y. Wu, L.Y. Bao, Z.H. Yang, New Carbon Mater. 22, 53 (2007). 